\title{
LONG-RANGE PLAN FOR A RESEARCH PROJECT ON CARBON MONOXIDE PRODUCTION AND PREDICTION
}

\section{William M. Pitts}

U.S. DEPARTMENT OF COMMERCE Natlonal Instltuto of Standards and Technology Natlonal Englneorling Laboratory Center for Fre Research Galthersburg, MD 20899 


\section{NATIONAL INSTITUTE OF STANDARDS \& TECHNOLOGY \\ Research Information Center \\ Gaithersburg, MD 20899}




\section{LONG-RANGE PLAN FOR A RESEARCH PROJECT ON CARBON MONOXIDE PRODUCTION AND PREDICTION}

\section{William M. Pitts}

U.S. DEPARTMENT OF COMMERCE Natlonal Institute of Standards and Technology Natlonal Englneerlng Laboratory Center for Flre Research Galthersburg, MD 20899

May 1989

Issued October 1989

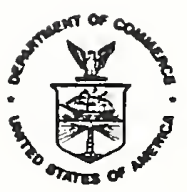

U.S. DEPARTMENT OF COMMERCE Robert A. Mosbacher, Secretary NATIONAL INSTITUTE OF STANDARDS AND TECHNOLOGY

Raymond G. Kammer, Aeting Director 


\section{ABSTRACT}

This document presents a five-year plan for the Center for Fire Research (CFR) Priority Research Project on Carbon Monoxide Production and Prediction. Sections of the report provide a justification for the priority project, assess the current state of knowledge, summarize current relevant CFR research efforts, discuss specific research needs, list major assumptions utilized in formulating the research program, outline a research plan designed to meet the goals of the project and address the specific research needs, provide a rough timetable and budget, and present a discussion of the project philosophy and management. 



\section{INTRODUCTION}

This document presents a five-year plan for the Center for Fire Research (CFR) Priority Research Project on Carbon Monoxide Production and Prediction. The overall goal of this project is to improve the understanding of and predictive capability for the formation of carbon monoxide (CO) in fires. The principal emphasis is on fires located within compartments since the ultimate motivation for the project is the large number of fire fatalities which result from the generation and transport of high concentrations of this toxic species.

In preparation for formulating this plan the author has performed an extensive review of the existing literature and relevant intramural and extramural CFR research programs. An important component of this review is the findings of a Workshop on Developing a Predictive Capability for CO Formation in Fires which was held in Clearwater, Florida on December 3-4, 1988. Leading experts in the field have provided recommendations and justifications for the principal areas in which research is required in order to achieve the ultimate project goal. An executive summary of this workshop is available [1].

In the following sections a justification for the priority project is provided, the current state of knowledge is briefly assessed, current relevant CFR research efforts are summarized, specific research needs are discussed, major assumptions utilized in formulating the research program are listed, a research plan designed to meet the goals of the project and address the specific research needs is outlined along with a rough timetable and budget, and a discussion of the project philosophy and management is presented. 


\section{JUSTIFICATION FOR A PRIORITY PROJECT ON CO PREDICTION}

One of the mandates of the Center for Fire Research is a reduction in the number of fire deaths and injuries. To achieve this goal, CFR has led the effort to characterize and model fire behavior. The development of realistic fire models allows strategies to be developed for ameliorating its effects. Investigations have shown that a large percentage of fire deaths and injuries can be attributed to products of combustion. Even in cases where burn injuries and death occur, incapacitation of victims by fire gases often plays a pivotal role since escape from flames is hindered or rendered impossible. Careful studies (e.g., [2-3]) have shown that more than one half of all fire victims have fatal levels of carboxyhemoglobin in their bloodstreams.

Even if a complete understanding of the physiological effects of CO (in combination with effects due to other fire products, e.g., reduced oxygen and increased respiration resulting from elevated carbon dioxide concentrations) is available, accurate predictions of fire toxicity require reliable estimates for the concentrations of toxic gases generated by a fire.

\section{ASSESSMENT OF THE CURRENT UNDERSTANDING OF CO FORMATION IN FIRES}

Systematic investigations of $\mathrm{CO}$ formation in fires date from at least the 1960s. However, despite nearly three decades of research the current understanding of $C O$ formation in fires must be characterized as poor. This is true despite the fact that it has long been recognized that co produced in fires is the principal gaseous species responsible for fire deaths. 
Numerous large-scale enclosure fire tests have been reported in which cO concentrations have been measured (e.g., [4-5]). These tests show unequivocally that co concentrations high enough to be life-threatening often occur in this type of fire. On the other hand, no systematic investigations of co formation in full-scale tests have been identified in the literature, and the conditions necessary for the generation of high levels of CO are not well characterized. The uncertainties are compounded by variations in experiment protocols (e.g., probe placement) and the utilization of inadequate experimental instrumentation.

In general, high $C O$ concentrations are associated with either smoldering or underventilated fires. Smoldering fires will not be considered here since other Center projects deal with this topic. Some crude correlations of co formation and the ventilation parameter ( $\mathrm{Ah}^{\frac{1}{2}}$ ) have been attempted [6]. However, the fire behaviors in these studies have not been adequately assessed, and the utility of these correlations for actual fires is limited. For locations removed from the room of origin, $C O$ concentrations are believed to depend critically on whether or not additional combustion of product gases occurs after exiting the enclosure. The understanding of this process is very poorly characterized, and the controlling parameters have not been identified.

George Mulholland has developed a zero-order model for co formation in room fires [7] which assumes very low concentrations of $C O$ for preflashover conditions and significant $C O$ concentrations for postflashover fires. CO concentrations following flashover are estimated to be 0.5 times the carbon dioxide concentration. This model is based on measurements recorded in three series of full-scale fire tests performed at CFR. 
In recent years some carefully performed experiments have been carried out which offer the promise of an improved understanding of $c 0$ formation in terms of engineering correlations. Workers at Harvard [8] and Cal Tech [9] have generated controlled two-layer combustion systems which closely mimic the simple two-layer model often used to represent enclosure fires. Note that, in general, these experiments are steady state while actual fires are highly dynamic. A remarkable finding of these experiments has been that the major products of combustion (including $\mathrm{CO}$ ) for a given fuel can be correlated in terms of the global equivalence ratio in the upper layer containing the combustion products. The correlations do depend on fuel type. Recent work [9] has shown that the same correlation holds even for the cases where additional air is injected into the upper layer. It should be noted that $\mathrm{CO} / \mathrm{CO}_{2}$ ratios measured in these experiments do not achieve the level of 0.5 assumed by Mulholland based on results in full-scale studies [7].

Very recently, the Cal Tech workers have extended their studies to an experimental configuration where the entire flame is located within the upper layer [10]. For this case, burning occurs entirely within a vitiated atmosphere. The rather surprising observation (based on earlier speculation in the literature) is made that very low concentrations of $\mathrm{CO}$ are measured for increasing fuel equivalence ratios up to the point where oxygen concentration in the vitiated environment $(\approx 138)$ is insufficient to support combustion. Similar observations have been made here at CFR for preliminary measurements in a cone calorimeter modified to allow partial vitiation of the air supply. These studies indicate that vitiation of the air supply is not responsible for high levels of $\mathrm{CO}$ as long as sufficient oxygen is available for complete, fully-involved combustion. 
In the past few years computer models have become available which allow the solution of the complex kinetic equations for chemical reactions and molecular transport in simple combustion systems [11]. Schemes involving reduced-kinetic mechanisms to lower the computational overhead are also under development [12]. Even though complete treatment is not currently possible (e.g., soot formation cannot yet be handled), insights concerning the behavior of simple products of incomplete combustion is possible. The same techniques should be especially useful for analyzing whether or not upper layer chemistry is important in compartment fires for a given equivalence ratio, residence time and temperature.

Significant efforts are underway worldwide to develop models which are capable of predicting the behavior of turbulent combusting flows. Fires fall into this classification. The highly complex natures of both combustion (complex chemistry and molecular transport) and turbulence (wide range of spatial scales required to characterize the phenomena) have proven to be very difficult obstacles to the successful development of practically-useful models. Several promising avenues continue to be investigated.

\section{CURRENT INTRAMURAI AND EXTRAMURAI CFR RESEARCH IN PRIORITY AREA}

At the present time there are no extramural grants dedicated principally to the CO Production and Prediction priority project and the only intramural research funded directly by the project are the experimental turbulent mixing project and support for an analysis (with regard to co formation) of experimental data from the Sharon, PA fire simulation and cone calorimeter experiments utilizing vitiated air. As evidenced by this report, current funding is primarily directed to providing a detailed project plan. 
Despite the fact that the total resources specifically dedicated to the project are very small, the actual Center effort related to co Production and Prediction is quite substantial and has achieved significant progress during the past few years. There are two principal reasons for this apparent contradiction:

- The first is that $C O$ formation is a problem which is central to fire research. Research efforts which are nominally dealing with a different aspect of fire have components which directly impact the co Prediction priority project.

- The second is the fact that by merely designating Co Production and Prediction as a priority research area and appointing a staff member to act as director and research coordinator has resulted in enhanced visibility for the project and, particularly for many of CFR's grantees, significant redirection of some projects toward consideration of problems relevant for this research topic.

Many current in-house programs of the Center have direct impact on the $\mathrm{CO}$ Production and Prediction priority project and, in turn, are influenced by the existence of the project. Several examples are cited here.

- Mr. K. D. Steckler's project on wall burning in a reduced-scale enclosure included sufficient measurements of gaseous species and flow rates to allow a crude test of the global equivalence ratio concept for the correlation of $\mathrm{CO}$ in a somewhat more realistic fire environment than earlier laboratory experiments. This analysis is in progress.

- The simulation of the Sharon, PA townhouse fire organized by Dr. R. S. Levine and Mr. H. E. Nelson was designed especially to study the release and transport of toxic gases. This experiment provides new insights into the formation of $\mathrm{CO}$ in "real" fires.

- The effort by Mr. R. D. Peacock to develop a data base of large-scale fire tests should provide new information and means for assessing the concentrations of $\mathrm{CO}$ generated by "real" fires.

- One of the Center's cone calorimeters has been modified to allow burning in a simulated vitiated environment. Measurements in this system are being utilized to assess the importance of vitiation on CO formation.

- Very simple models of CO formation are being incorporated into FAST and Hazard I for predictive purposes. Longer-term efforts on chemically reacting turbulent flows are expected to provide the means 
for introducing appropriate "source terms" into fire models. The ability to predict $C O$ formation will be one of their primary functions. Theoretical efforts by Dr. H. R. Baum and the experimental efforts of Dr. W. M. Pitts feed into this effort.

Much of the Center's current experimental effort on CO Production and Prediction is taking place in extramural research efforts sponsored by other groups, or which are in support of other priority research areas. Examples are cited below.

- Professor E. E. Zukoski's studies are continuing with the oversight of Leonard Cooper, leader of the CCFM priority project. As already discussed, the findings of this study along with a companion study at Harvard which ended several years ago are providing significant insights into $\mathrm{CO}$ formation in fires.

- Professor R. J. Roby (in collaboration with Dr. C. L. Beyler) is developing a reduced-scale experimental system for investigating fires in enclosures for a project which is being monitored by $\mathrm{Dr} . \mathrm{H}$. E. Mitler. These experiments should provide additional insights into the appropriateness of utilizing the global equivalence ratio concept for correlating $C O$ formation in fires and generate a new understanding as to the role of combustion outside of the enclosure in determining the final concentrations of $\mathrm{CO}$ delivered by a fire.

- Professor R. J. Santoro is currently working on a project associated with the Soot Formation and Evolution priority project. As a part of this effort he has begun measurements designed to investigate whether there is a correlation between the amount of soot released from laminar flames and $C O$ production. This is a fundamental area, where little previous work is available, which might be very important for understanding the mechanisms of CO formation.

- Professor J. H. Miller of George Washington University is working on a fundamental study of combustion chemistry designed to improve the understanding of soot formation in fires. He has recently considered the implications of his measurements in laminar diffusion flames for CO formation in fires. His analysis has helped clarify why global kinetic expressions are not appropriate for predicting $\mathrm{CO}$ concentrations.

- Professor G. M. Faeth of the University of Michigan, stimulated by his participation in the recent workshop on CO formation, plans to make careful measurements of $C O$ concentrations above his buoyancyariven turbulent flames. Prior to this time, $\mathrm{CO}$ has been treated as a minor product and careful measurements were not made.

- The CFR-supported program at Factory Mutual Research Corporation has components which impact on the CO Formation priority project. These 
workers are considering incorporating a project aimed specifically at this problem.

\section{SPECIFIC RESEARCH NEEDS}

\subsection{Workshop Findings}

The findings of the recent workshop on "Developing a Predictive Capability for CO Formation in Fires" provide an excellent starting point for a discussion of the research, required to meet the goals of the Carbon Monoxide Production and Prediction priority project. For convenience sake, the final conclusions and recommendations for the workshop [1] are reproduced here. The priority assigned to each area is given roughly by the order of presentation (the highest is first). The workshop executive summary should be consulted

for additional background material and discussion.

1. Experiments clearly suggest that high concentrations of co result principally from burning in underventilated conditions. The degree of vitiation appears to be important only when oxygen concentrations are too low to support combustion. Experiments and theoretical efforts are required to understand the formation mechanisms of and to allow prediction of high $C O$ concentrations. Such studies should be assigned the highest priority. Investigations of laminar flames and buoyancydriven turbulent flames are both necessary.

2. Existing experimental diagnostic techniques do not provide adequate capabilities to answer the questions which must be addressed when $C O$ formation in fires is considered. The lack of suitable diagnostics represents a serious hinderance to the priority project and must be addressed. Inadequacies are apparent in all experiments from the smallest laminar flame to full-scale turbulent fires. Principal problems are the absence of suitable sampling techniques and the presence of soot in fires which acts as an interferant and, at the same time, must also be characterized. Existing diagnostic methods must be improved and more carefully applied and new methods capable of time- and space-resolved concentration and/or temperature measurement in sootladen flows developed. Particularly important needs are for techniques which allow local and global equivalence ratios to be determined accurately.

3. The observation that $C O$ concentrations can be correlated in terms of the global fuel equivalence ratio provides the most logical starting point 
for an engineering correlation of CO production within enclosures. Theoretical efforts are necessary to allow the correlation in terms of the global equivalence ratio to be understood in terms of the local combustion environment within the combusting plume. Laminar flamelet theory provides the most logical starting point for these efforts. Experiments are necessary to characterize the conditions for which the global fuel equivalence ratio concept is valid and to verify whether or not it can be extended to developing full-scale fires.

4. The understanding of the combustion behavior of upper layer gases emitted through a vent in an enclosure containing a fire is very poor. Experiments must be formulated which determine the parameters which control this process and correlations and/or theoretical models must be developed which allow the degree of $\mathrm{CO}$ burnout to be estimated as a function of appropriate fire conditions.

5. The role of "upper-layer chemistry" must be clarified. Conditions (chemical and thermal) where the upper layer continues to react and for which it is passive (with regard to additional Co formation or removal) need to be identified. Full kinetic calculations and reduced mechanisms offer particular promise for this problem. The role of inhomogeneous chemistry must be experimentally investigated and incorporated into kinetic models.

6. Scaling effects must be investigated. It is recognized that full-scale testing is necessarily limited and that experiments on smaller scales must be devised. This is only possible if scaling effects are characterized.

\subsection{Discussion of Research Requirements}

The members of the workshop have done an outstanding job of identifying the principal requirements of a coherent research program designed to address the need for the development of $\mathrm{CO}$ predictive capabilities. The workshop was composed of members who reflected both fundamental and engineering approaches to the problem and the recommended research programs are a balanced representation of both research strategies. Note that the actual recommendations are not based on this criterion.

There are a number of less specific requirements which must be addressed during the proposed priority project. For instance, up to now there has been no systematic analysis (beyond the necessarily brief review by Mulholland [7] 
which only considered three sets of data) of existing full-scale fire test data to ascertain what can be learned concerning the formation of $\mathrm{CO}$. Such an analysis is not straight-forward. Large-scale fire tests are generally not designed to investigate the generation and movement of toxic gases. Gas sampling positions in different tests are highly variable and the accuracy of the reported measurements is often suspect and uncharacterized. The development of a large-scale fire test data base should prove very useful. It is clear that the CO Production and Prediction project should provide input as future large-scale tests are being planned in an attempt to improve the impact of these tests on the understanding of CO formation.

The six areas listed in the last section provide a general outline of the research which is necessary to meet the goals of the priority project. In order to be successful the five-year plan must effectively incorporate efforts in each of these areas. In addition, an effective management strategy must be employed to ensure that effective communication and feedback exists between the various (and seemingly disparate) parts of the project and that potential users of the results (i.e., fire modelers) are kept apprised of progress and provide feedback concerning their requirements.

In order to outline a program dealing with a such a complex research question as CO formation and prediction, which involves a large number of researchers and disciplines, it is necessary to make certain assumptions concerning the resources and time available. Other assumptions must be made also. These are discussed in the Section 6 .

In Sections 7-9 a program is described which effectively addresses each of the six research areas suggested by the workshop members. A table of more specific components is also provided. In some cases these components are 
currently part of the Center's projects. In other cases, new research efforts are required and examples of researchers and/or organizations having suitable expertise are identified for informational purposes. Cost estimates are included in Section 8. A description of the management structure to be employed appears in Section 10.

\section{Project Assumptions}

Several assumptions have been utilized in the development of the research plan which is presented in Sections 7-9. The most important are discussed here.

\subsection{Research Approach}

In order to have an effective and broad project on co Prediction it is necessary to pursue both fundamental and engineering approaches to the problem. Even though no clear demarcation exists between the two approaches, it is generally possible to characterize various research efforts as being one or the other.

The current state of knowledge suggests that the engineering approach is more developed and offers the most viable near-term means for the development of correlations which can be incorporated into existing CFR models of fire behavior. Fundamental research is required to provide an understanding of the physical and chemical processes underlying the engineering correlations and to allow these findings to be extrapolated to cases where experiments have not been performed. A more fundamental understanding will become crucial as efforts are made to incorporate realistic chemistry and physics into the "source terms" of fire models. 
It is assumed that the priority project will last for a five-year period. As in the majority of research projects, this estimate of the period required to complete the project is based on the expectation that no major "surprises" occur during the project and that the assumptions made concerning the current state-of-knowledge will be shown to be correct.

\subsection{Project Goals}

Clearly the general goal of improving the understanding of and predictive capability for the formation of $\mathrm{CO}$ in fires is far too general to serve as a legitimate measure of project success. More specific goals (milestones) must be formulated. The following milestones in terms of the engineering and fundamental components of the project represent realistic goals for the fiveyear program.

1. By the end of the third year of the project an engineering correlation for $C O$ concentrations in terms of the global equivalence ratio will be available for incorporation into fire computer models. Further work during the final two years of the project will be required to fine tune this correlation and determine the appropriate conditions for which its use is valid. By the end of the five-year period it will be possible to incorporate the effects of the combustion behavior of products exiting an enclosure on CO formation.

2. By the end of the five-year period the fundamental portion of the project will have identified the important parameters controlling $C O$ formation in fires. A general understanding of the reasons for the success of the global equivalence ratio concept in terms of the combustion behavior within the plume will have been attained. Modelling of CO formation for very simple systems (e.g., a single gas burner located in an enclosure) will be possible. Treatment of more complex configurations and fuels will not be possible in the absence of significant advances in other Center priority projects. 


\subsection{Availability of Project Resources}

The availability of resources is a key component in the successful conduct of the priority project. In order to prepare a realistic project plan, it is necessary to assume that certain resources will be provided. As described in Section 4 and enumerated in Section 8, significant Center resources are currently directed at the project despite the fact that most of these efforts are not currently targeted specifically on the co formation problem. As the research project becomes more highly focused and developed, it is assumed that a rough doubling of the current funding commitment will be needed. These additional funds will be used to augment existing research programs and initiate new efforts which are not currently part of the Center program.

\subsection{Assumptions Concerning Current Understanding}

In this section some of the assumptions which are being made concerning appropriate research approaches are discussed. This topic is included here since the success of the project in attaining its goals will be strongly tied to the appropriateness of these assumptions.

A major assumption of this work is that the global equivalence ratio concept offers a means for correlating CO production in real fires. Some confidence is gained by the success of this approach in well-controlled laboratory experiments. However, it must be remembered that no scaling studies have been performed and that upper-layer temperatures in the laboratory experiments are not generally as high as attained in actual fires. The global equivalence ratio concept could fail in either of these situations. If this occurred, a new approach for an engineering correlation would need to 
be adopted and the time table for the development of an useful correlation would certainly slip.

A more subtle problem is implied by the inclusion of area 2 in the recommended research areas listed in Section 5.1. It is assumed that it will be possible to verify the global equivalence ratio concept for large-scale fire tests. Such a verification requires accurate gas species measurement within the upper layers of large-scale fires. However, it is unclear if the necessary species measurements can be performed in such an environment utilizing existing experimental diagnostics.. The uncertainty involved here is the major reason members of the workshop recommended that diagnostic development be assigned such a high priority in a project on co formation [1]. For the purposes of planning it must be assumed that experimental measurements which are accurate enough to verify or disprove the global equivalence ratio concept for full-scale fires will be available within the projected project time frame.

The research effort on the fundamental side requires assumptions which are even less certain than for the engineering side. This is usually the case for research projects aimed at both fundamental understanding and engineering solutions. The assumption that suitable diagnostics will be available is more crucial. In order to improve the fundamental understanding of co formation, time- and space-resolved measurements within combustion regions of laminar and turbulent buoyancy-driven flames will be required. Here the lack of suitable diagnostics could prove debilitating to the project.

Models have been developed for treating combusting, buoyancy-driven turbulent flows. The most widely employed is the laminar flamelet model [13] incorporated into suitable turbulence models. This approach has been used for 
a large number of combustion systems. It must be remembered that Professor Bilger of the University of Sydney has questioned the basis for the laminar flamelet concept and has suggested that reactions may actually be distributed in broad regions of the plume [14]. The most widely utilized turbulence model for predicting turbulent behavior is the $k-\epsilon$ model. No attempts have been made to use the $k-\epsilon$ model and laminar flamelet concept for predicting the high levels of $\mathrm{CO}$ generated by fires in enclosures. It will be assumed that the laminar flamelet concept in conjunction with the $k-\epsilon$ model for turbulent mixing provides a viable approach for modeling co formation. This hypothesis must be carefully tested. If it turns out to be incorrect, the development of models for treating $C O$ formation in simple configurations could be delayed significantly.

\section{PROPOSED RESEARCH ACTIVITIES}

A coherent research plan is crucial if both the fundamental and engineering approaches to the CO Production and Prediction priority project are to make substantial progress. In some cases, necessary research is in progress or is planned, and it is only necessary to proceed along an existing path. In other cases, new programs must be nurtured either here in the Center or by the extramural research program.

The areas of research listed in Section 5.1 provide a good starting point for the discussion. Additional research areas will also be mentioned. For those cases where existing Center programs are in place, the relevant programs will be mentioned. In some cases existing research efforts have importance for two or more of the research areas. Other subjects are not currently part 
of the Center program. Examples of researchers currently working in related areas are provided.

\subsection{Required Research Components}

\subsubsection{Fundamental and Engineering Investigations of Underventilated Flames}

Previous research findings strongly suggest that high $\mathrm{CO}$ concentrations occur principally for underventilated burning. Most past combustion research has not considered this problem. A few laminar flame studies are reported in the literature and the Center has ongoing efforts on enclosure fires which are relevant (in particular, the grant projects of Professors Zukoski and Roby and the wall burning study of Mr. K. D. Steckler).

The work at Cal Tech has made very good progress in the past and continues to do so. Professor Zukoski completely understands the importance of his work to the CO Prediction priority project and has been responsive to its needs. One limitation of the work is that it has not considered fuel effects. Investigations of fuel effects are proposed for the next three-year cycle.

Professor Roby plans to investigate burning in a reduced-scale enclosure for a variety of fuels. The measurements generated by this grant program will be directly applicable to the CO Production and Prediction priority project and should complement the work of Professor Zukoski. This program should be closely monitored to ensure compatibility with both the CCFM and CO Prediction priority projects.

Currently there is no Center program on underventilated burning of simple laminar flames even though some preliminary experiments have been reported in the literature. Given the high importance assigned to this research area, a 
new effort should be initiated in this area with a general goal of identifying the fundamental chemistry and physics responsible for the formation of high levels of $\mathrm{CO}$ during underventilated combustion. A large number of fuels should be utilized in order to characterize the importance of fuel effects on CO formation. This study will not only provide an improved understanding of any engineering correlations which are developed, but will also be absolutely essential as more fundamental models for fire source terms are developed.

Many researchers have the necessary background and technical expertise to initiate a program on underventilated burning. The necessary expertise is located here in the Smoke Dynamics Research Group and at a number of universities. Examples of research groups having such capabilities include workers who are currently supported by the CFR extramural program such as Professors Faeth, Santoro, or Miller, and others such as researchers at Princeton, Stanford, or the University of California campuses of Berkeley, San Diego, Irvine, or Los Angeles.

\subsubsection{Development of Flame Diagnostics}

At first glance it might appear as if the development of accurate measurement techniques for flame gases is outside the scope of this priority project, but the members of the workshop rated the development of new diagnostics for chemical species as being critical to success. Such development is viewed as being particularly relevant when measurements in flame regions with high soot concentrations must be made. Current methods for species measurements are subject to a variety of uncertainties, and no systematic investigations of the effects of flames on probe sampling of gases of interest are available. This is true despite the fact that some members of 
the research community have argued that many past measurements of $C 0$ in flame regions have had large systematic errors.

The accurate measurement of flame gases in regions of high temperature is important to both engineering and fundamental approaches. One of the basic questions which must be answered in developing correlations for co formation is the effect of additional combustion outside of the room of origin on the final concentrations of CO delivered by a fire to remote locations. This question can only be answered satisfactorily if accurate measurements of flame gas concentrations are available both within and removed from the room of fire origin. Measurements must be made for both large-scale and reduced-scale fire tests. Since the upper layer temperatures in actual fires can reach temperatures of approximately $1300 \mathrm{~K}$, accurate gas sampling for temperatures at least this high must be possible.

In attempting to develop more fundamental approaches for understanding CO formation the requirements for gas sampling become even more severe. One of the principal goals of the priority project is to understand the success of the global equivalence ratio concept in terms of the behavior of the turbulent plume. Such an understanding requires that gas concentrations be available with high spatial and temporal resolution. It is safe to say that at the present time no suitable technique for such measurements has been demonstrated for sooting turbulent flames.

The lack of suitable diagnostics may turn out to be the largest roadblock on the pathway to an improved understanding of $\mathrm{co}$ formation. For this reason, it is recommended that a component of the priority project be dedicated to the development and characterization of suitable diagnostics. The author has identified many researchers who have an interest in this problem, but none who 
have a strong record of demonstrated ability in this area. Within the Center Drs. G. W. Mulholland and T. Kashiwagi have expressed an interest in developing new diagnostics, and Dr. K. C. Smyth and Professor J. H. Miller have developed specialized techniques for very weakly sooting flames. Workers at Factory Mutual Research Corporation seem to have taken the most care in developing probes which are properly "quenched", but careful testing of their probes has not been performed. Professor R. J. Santoro of Penn State has apparently made some progress in the development of a new probe which is not susceptible to soot clogging. This research should be monitored very carefully. Professor W. Grosshandler of Washington State University (currently at NSF) has also indicated that probes having the desired characteristics (at least for time-averaged measurements) can be developed $[15]$.

It is believed by the author that this area is one of the most crucial and, at the same time, uncertain research topics of the priority project. It is clear that some progress must be made if significant advances on the priority project are to be possible, but it is also clear that there are not sufficient resources available to have a wide-ranging program. It is suggested that current projects which have diagnostic development components (such as the projects directed by Dr. T. Kashiwagi, Dr. K. C. Smyth, and Professor R. J. Santoro, and the Factory Mutual Research Corporation work) be monitored very carefully and that these investigators be encouraged to work along these lines. One project devoted entirely to measurements of flame gases should be supported by CFR. This research project may turn out to intramural or extramural. 


\subsubsection{Use of The Global Equivalence Ratio Concept}

Research findings suggest that the correlation of $C O$ concentrations in terms of the global equivalence ratio in the upper layer provides the most viable and best-developed approach for incorporating CO formation into existing Center fire models. Before this can done with confidence several experiments must be performed. Some of these experiments have been deemed important enough to be included as separate research areas. Thus research areas 4-6 in Section 5.1 provide information which is required before the concept can be applied with confidence to full-scale fires.

Other projects which impact on this area are discussed here. In area 3 of Section 5.1 it is pointed out that theoretical efforts are required to allow the success of the global equivalence ratio in correlating co formation to be understood in terms of the behavior of the turbulent plume. The most logical starting point for such a study is to utilize the laminar flamelet model with the $k-\epsilon$ turbulence model and attempt to perform a calculation which mimics the experimental arrangement of Professor Zukoski and his coworkers.

As a first approximation the behavior of the combusting buoyant plume below the upper layer can be treated as a fully-ventilated, free combusting plume. The calculation can be used to solve the problem for the flow until a downstream position is reached where the interface between the upper and lower layers is located. This is a standard calculation which has been previously tested. The results of this calculation can then serve as the starting conditions for a reacting plume flowing into surroundings with the same composition of the upper layer. For a first attempt, the upper layer will be assumed to be infinite and recirculation effects and quenching ignored. The correctness of these assumptions can be tested by comparison of the calculated 
results with the experimental results when a hood is present. This extended calculation should provide an indication of whether or not such a modeling strategy offers a useful approach for understanding Co formation in fires.

In the above discussion it has been implicitly assumed that gas species and temperature will have the same dependence on the local equivalence ratio within the flame as found for fully-ventilated fires. This can not be confirmed without experimental tests. The experiments described above for laminar burning with underventilation should allow this hypothesis to be checked. If the hypothesis fails, the observed dependence of gas species on the local equivalence ratio can be incorporated into the model.

There are a number of laboratories which are capable of performing the computational study outlined here. Professors J. P. Gore and G. M. Faeth (current CFR grantees) come to mind immediately. At the present time, the Center is not one of these. However, during the next fiscal year the Center is planning to procure a sophisticated computer program package named "Phoenics" from CHAM of North America. This package is designed to allow k- $\epsilon$ modeling of combusting flows. The problem outlined here would provide an excellent opportunity to exercise this code for a problem of great interest to the Center. Assuming the availability of the code, this part of the program should likely be performed within the Center.

It is clear that more fundamental models of chemically reacting turbulent flows will ultimately be required to model accurately the formation of $\mathrm{CO}$ as well as many additional "source terms" for fire models. The Center priority project on Turbulent Combustion is performing long-range research in this area. The experimental program on turbulent mixing is currently being supported by the CO Prediction priority project. This project will eventually 
contribute to modeling of fire "source terms" as well as an understanding of Co formation. Like many of the Center's programs, the turbulent mixing project is interdisciplinary, and it has potential impact on a number of the priority projects. It should be maintained as part of the long-term efforts on modeling of plume behavior, chemically reacting turbulent flow, and co formation.

\subsubsection{Effect of Combustion of Upper-Layer Gases Outside of the Enclosure}

The gases and soot particles which form the upper layer of enclosure fires are often found to be highly vitiated and fuel rich. The fuel stoichiometry is generally rich enough to support combustion when these gases are mixed with air containing sufficient $\mathrm{O}_{2}$. When these gases exit the enclosure through vents, additional combustion is frequently observed at locations where these gases contact higher concentrations of oxygen.

Large number of uncertainties exist concerning this process. The conditions required for such burning are not characterized, and the degree to which such burning can remove the partially-pyrolized fuel has not been determined. It is generally believed that combustion of this type results in less co being delivered at positions away from the fire, but one can imagine conditions of partial combustion where higher $\mathrm{CO}$ levels would be produced. Clearly, the behavior of such burning is one of the major areas of uncertainty concerning the formation of $\mathrm{CO}$ in fires.

Even though this type of behavior has significant implications for many fire research applications (e.g., fire safety and fire spread), there has been no systematic investigation of the problem. Currently, Professor Roby is setting up an experiment in which he plans to make observations concerning 
such burning. Hopefully, this project will provide reliable data and allow some preliminary engineering correlations (insights?) to be developed.

With regard to full-scale fire testing within the Center, if careful measurements of gas concentrations (particularly $\mathrm{CO}$ ) can be made at the exit and downstream of the burning region outside of the enclosure, it should be possible to characterize the effectiveness of such burning in removing $C O$. Ultimately, a more fundamental approach will be required to deal with this aspect of fire behavior. However, in the absence of observational data and engineering correlations, this problem seems beyond the scope of the current priority project.

On the basis of the above discussion it is recommended that Professor Roby be encouraged to pursue his current studies on the burning of partiallypyrolized gases exiting his reduced-scale enclosure and that this work be monitored very carefully by Center personnel. If sufficient progress occurs, a project focused on this particular fire area should be initiated either here or in an extramurually-funded program if a suitable proposal is received for consideration.

In the meantime, consideration should be given to "piggybacking" on Center full-scale fire tests to make measurements of CO both within the upper layer of the fire enclosure and downstream of the position where burning has occurxed. Such measurements will certainly provide information concerning the effectiveness of this type of burning in removing (or creating) co.

\subsubsection{Stability of Upper Layers at High Temperatures}

The studies at Cal Tech have demonstrated that the concentrations of CO and other flame gases are stable for temperatures as high as $900 \mathrm{~K}$ [16]. This 
is encouraging since it suggests that it should be possible to ignore the effects of upper layer chemistry for temperatures below this level. However, temperatures in the upper layers of real fires have been shown to attain levels as high as $1300 \mathrm{~K}$. For these conditions it is conceivable that gas phase reactions occurring on a tens-of-seconds time scale could modify the CO concentration and invalidate the global equivalence ratio concept. It is also possible that chemical reactions can occur on the surfaces of soot particles at lower temperatures.

In order to develop a fundamental understanding of $\mathrm{co}$ formation in fires and identify the ranges of conditions over which the global equivalence ratio concept is valid, it is necessary to investigate both homogeneous and inhomogeneous chemistry in the upper layer.

Two different approaches should be adopted. Computer codes are available (such as those based on the Sandia Combustion Research Facility ChemKin package [11]) which allow quite complicated sets of chemical kinetic equations to be handled. Clearly, it will be impossible to treat all of the gas-phase chemical species in the upper layer using a full-kinetic treatment. However, it is expected that only species in relatively high concentrations will be important. This should allow the number of species involved and the total number of chemical reactions to be limited to realistic values.

A useful approximation will be to treat the upper layer as a well-stirred reactor at a given temperature. Initial concentrations of gas phase species (representative of the fire environment) can be input and the time history of the concentrations monitored. If the concentrations are calculated to be invariant for the time scales of interest (usually on the order of tens of seconds), the upper layer can be considered as being chemically passive. 
However, if strongly varying concentrations of $\mathrm{CO}$ are predicted, the upper layer must be considered as chemically active and the global equivalence ratio concept would be expected to fail in this case.

The use of full chemical-kinetic codes has proliferated during the past few years and the expertise for their use can be found at a large number of institutions. Professors P. R. Westmoreland at the University of Massachusetts and M. D. Smooke at Yale are two well-known workers in this area. There have also been recent attempts to mount these codes on CFR computers, and some progress has been made. However, much work remains to be done within the Center before meaningful, research-grade calculations can be attempted. The CO Prediction priority project offers an opportunity to incorporate this important capability into in-house Center projects.

Heterogeneous chemistry is much more difficult to model than homogeneous gas-phase chemistry. An experimental approach should be adopted for this part of the upper-layer stability problem. Furnace experiments can be devised in which soot from actual combustion process (or a suitable surrogate) are placed in a heated flow tube. Appropriate mixtures of $\mathrm{CO}, \mathrm{CO}_{2}, \mathrm{H}_{2}, \mathrm{O}_{2}, \mathrm{H}_{2} \mathrm{O}$, and other flame gases are allowed to flow through the heated tube containing the small solid particles and the chemical composition of the mixture at the end of the flow tube is monitored by an appropriate analytical technique such as gas chromatography or mass spectrometry.

As a first step, these experiments should be performed at temperatures low enough to ensure the absence of significant gas-phase reactions. If no important heterogeneous reactions are identified, it will be necessary to go to higher temperature where competition between homogeneous and inhomogeneous reactions is possible. In order to identify the role of inhomogeneous 
reactions it will be necessary to make measurements in the presence and absence of the solid phase particle. Full or partial modeling of the appropriate gas phase kinetic equations might also be useful here.

There have been some measurements of the role of solid particles and catalytic surfaces on the conversion of $\mathrm{CO}$ to $\mathrm{CO}_{2}$ (and vice-versa). However, there have been no studies concerned with the chemical stability of upper layers in fires. This is a new direction for fire research. The expertise for such a project exists within the Center, but a redirection of research effort and the development of a new apparatus would be required. Professor $W$. Grosshandler of Washington State University (currently a rotator at NSF) has expressed an interest in this problem and proposed to have a student work at the Center in conjunction with him (gratis, one day a week) on a simple flow reactor during the upcoming summer. This proposed summer project offers a viable means at a relatively low cost to either initiate a longer-term grant project in this area or to develop the necessary expertise within the Center.

\subsubsection{Scaling Studies}

This is the last of the major research areas listed by the workshop members. It reflects the fact that only limited numbers of full-scale fire tests will be possible for characterizing CO formation. It is almost certain that it will be necessary to utilize measurements in smaller-scale fires to provide the number of experiments required to cover the range of possible conditions necessary for useful engineering correlations and to characterize experimental variability.

In order to insure that the results of smaller-scale investigations are meaningful for full-scale fires, it will be necessary to investigate the 
scaling relationships between the smaller-scale and appropriately chosen large-scale experiments.

The most likely scenario for such a test is to compare the findings from the smaller-scale experiments which are currently being set up at VPISU with one or more (certainly a very few) full-scale experiments performed within the Center. It is possible that the full-scale test can be "piggy-backed" on a planned large-scale fire test, but it seems more likely that a speciallyplanned test(s) will be required. In any case, attempts should be made to compare the effectiveness of the global equivalence ratio concept in predicting $C O$ concentrations in the upper layers on each scale as well as the effectiveness of burning outside of the enclosure in removing $C O$. Before such a scaling test can be run, the proper scaling parameters must be determined for fire properties such as fuel loading, ventilation parameter, and fire heat release rate. Fortunately, there are a number of researchers in the Center, including Dr. J. G. Quintiere, who are experts in this research area. With these scaling laws it will be possible to construct a large-scale fire test specifically designed to test the scaling properties relevant to co formation.

\subsection{COMPONENTS OF THE RESEARCH PLAN}

The discussion thus far has identified the major research areas where work is required in order to improve the understanding of $\mathrm{CO}$ in fires and develop methodologies for its prediction. In this section, recommended specific components of the project are listed in tabular form (Table 1). Each is identified as being of an engineering, fundamental or dual nature. A short statement of purpose (goals) for each component is provided. Work currently supported by the Center (intramural or extramural) is 1isted. Either current 
researchers working on the problem or examples of researchers having the required expertise to work on the component are compiled. An estimate of the time required to achieve the goals of the component is provided along with an indication of timing for work on the component relative to the five-year period of the CO Production and Prediction priority project.

In a sense, this table provides a general summary of the five-year research plan for meeting the goals of the CO Production and Prediction priority project. It provides an indication of the complexity involved and the wide range of questions which must be effectively addressed before a useful understanding and a predictive capability for co formation is available. Note that each of the major areas of research recommended by the workshop participants is addressed by one or more of the research components included in the table.

\section{BUDGET FOR THE FIVE-YEAR PRIORITY PROJECT}

Table 1 lists the research components which have been identified as being required to make significant advances in the understanding and prediction of CO formation in fires. In this section estimates are provided for the annual funding levels required to support each of these components.

As has already been noted, significant research efforts of relevance to this project are being supported by CFR even though the funding is not allocated directly to the CO Formation Priority Project. Current expenditures for each of the eighteen project components have been estimated.

Table 2 lists each research component, whether CFR or grantees (assumes the submission and funding of appropriate unsolicited proposals) are projected to perform the work, an estimate of FY89 CFR expenditures on the component 


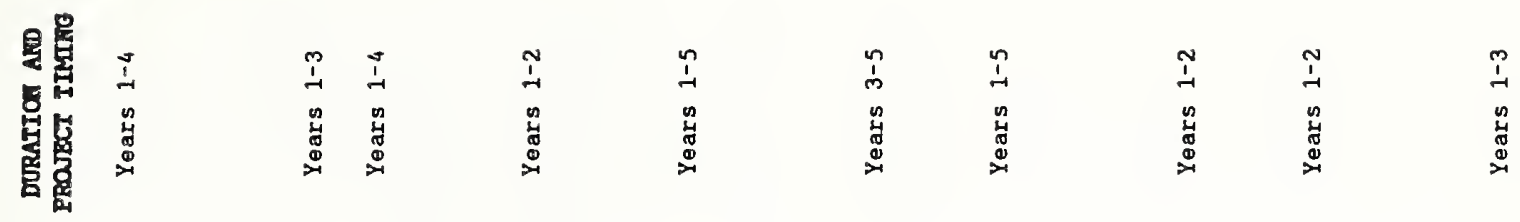

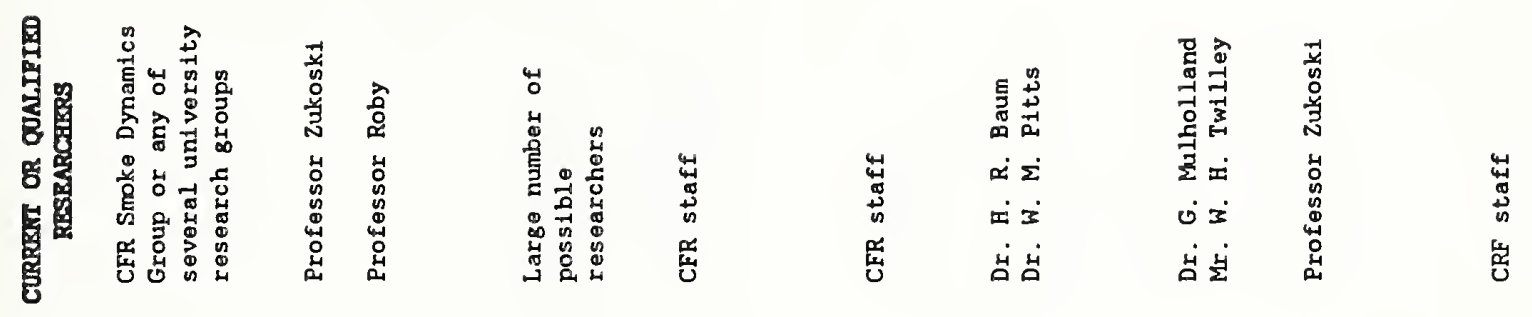

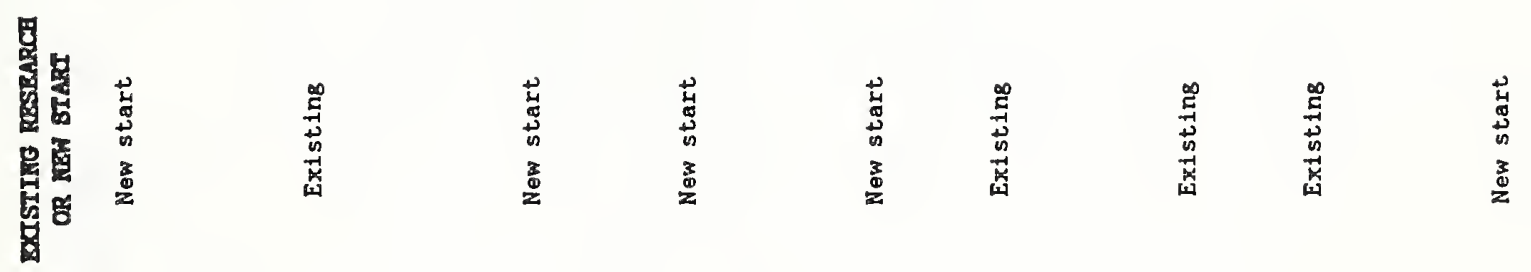

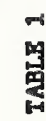

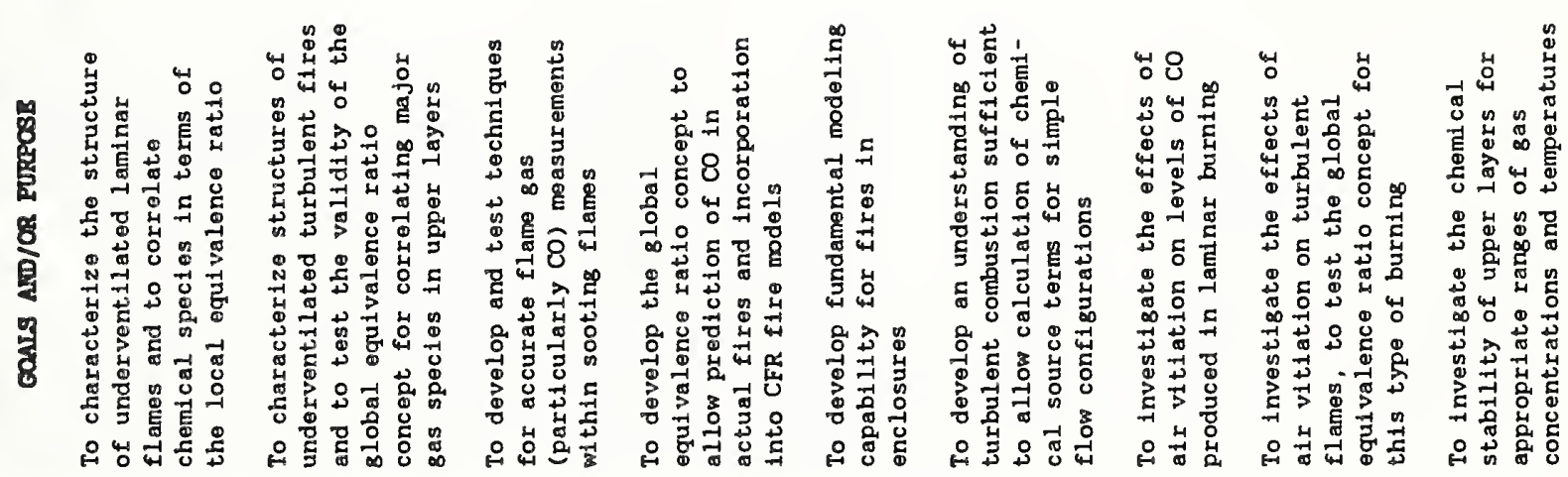

!I

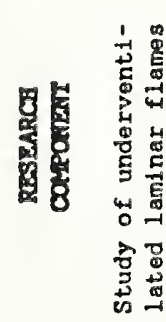

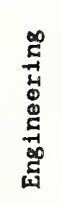

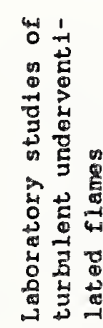

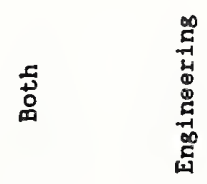

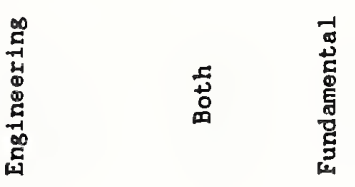

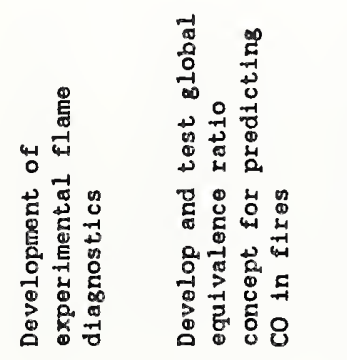

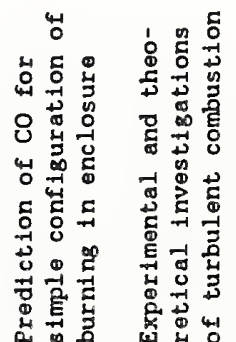

离

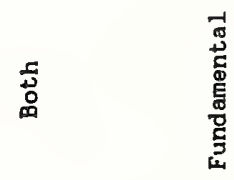

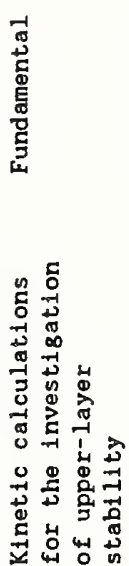




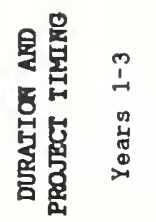

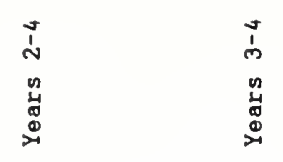

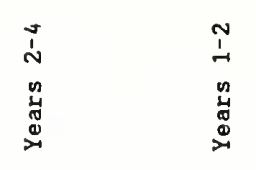

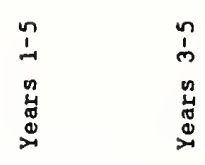

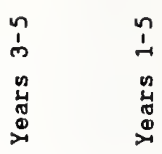
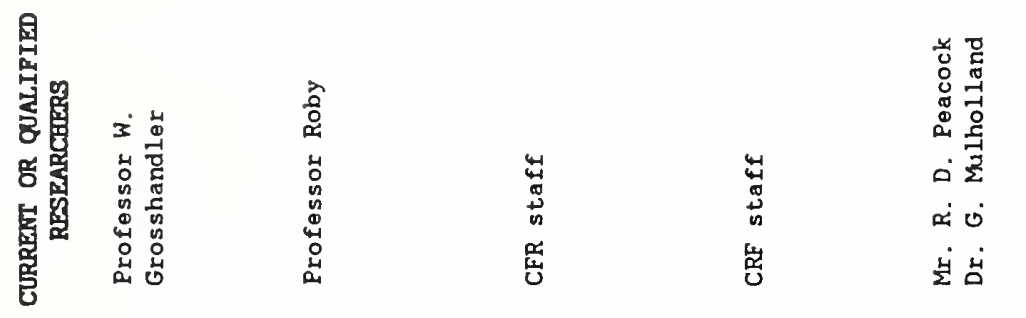

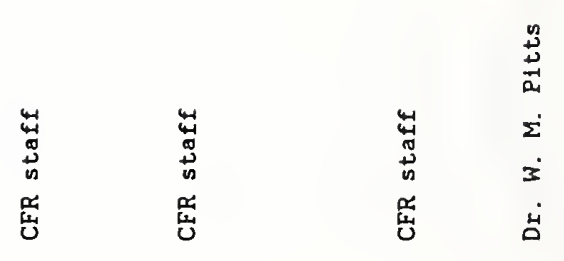

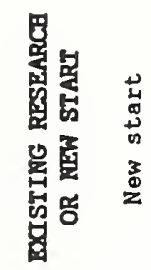

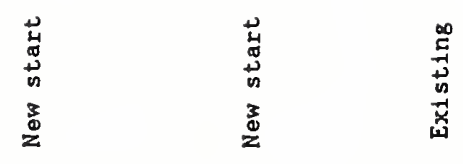

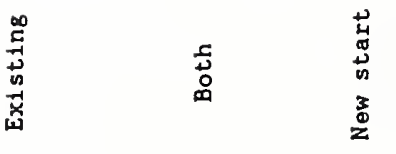

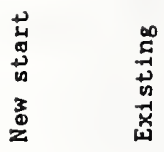

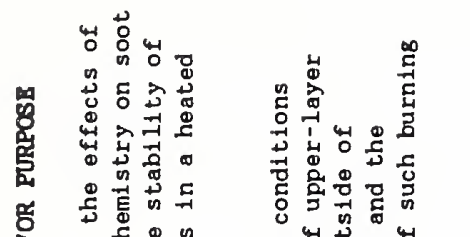

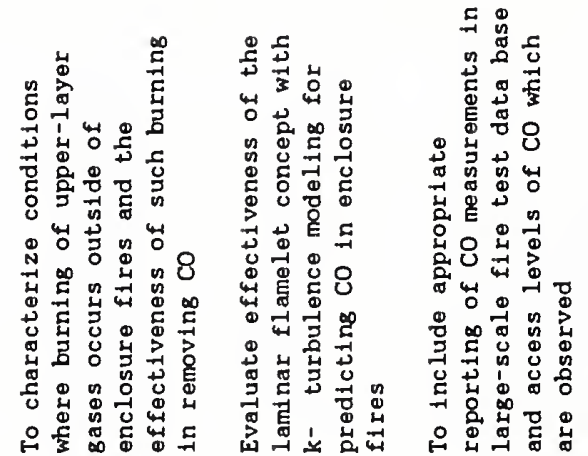

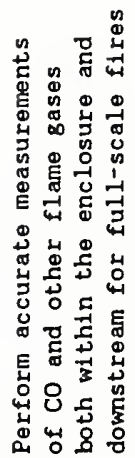

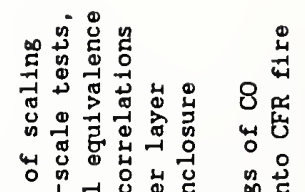

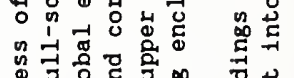
$\begin{array}{llllll} & \\ & & \\ 0\end{array}$

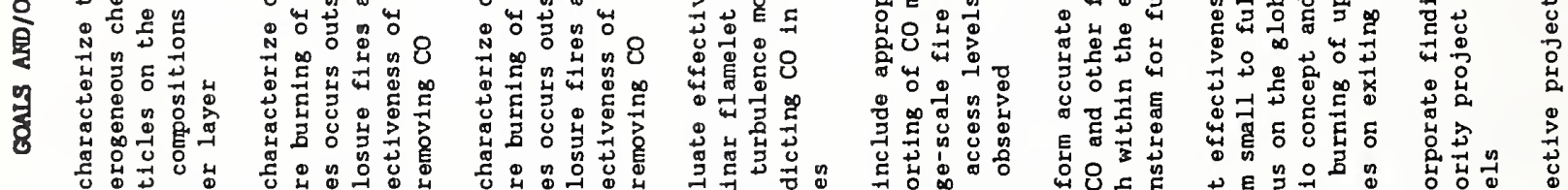

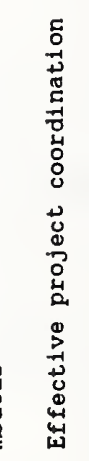

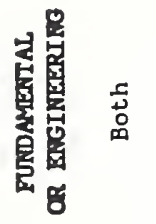

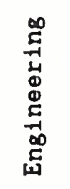

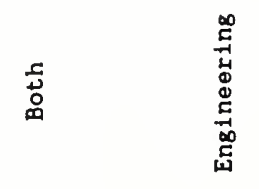
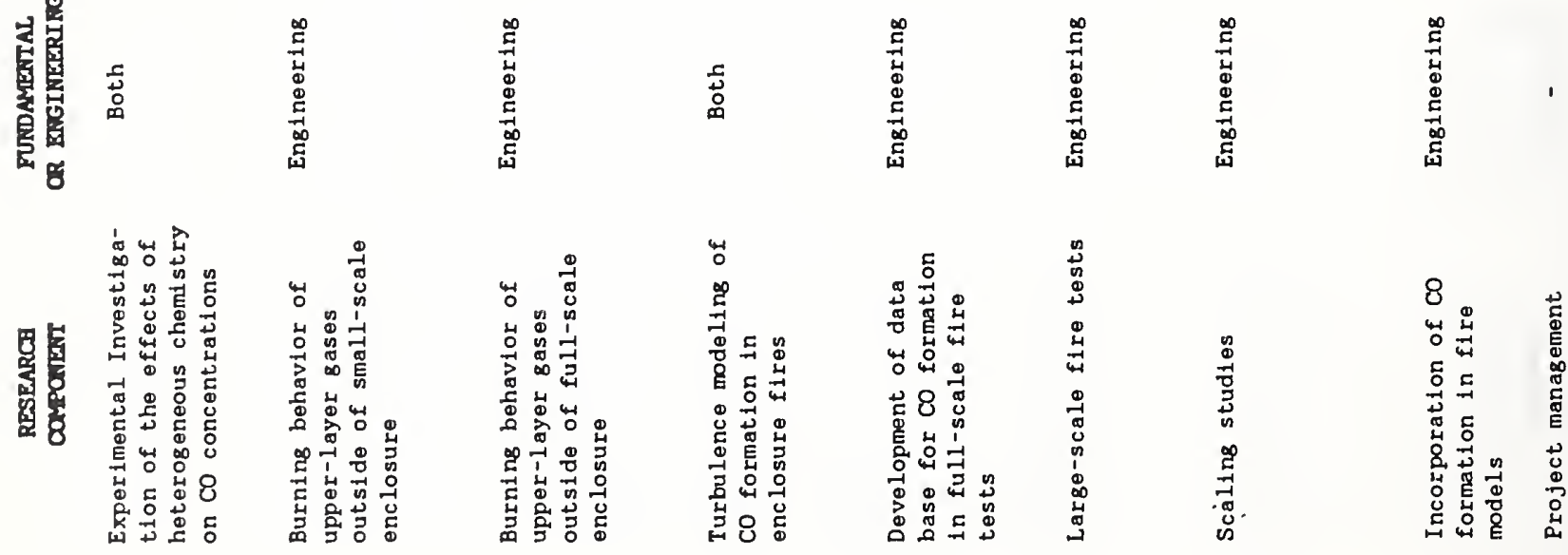

+ ㅇ

$\exists$

ㄱ

9

$=$

$n$

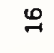

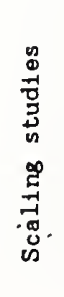

包

윤

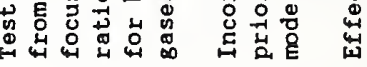

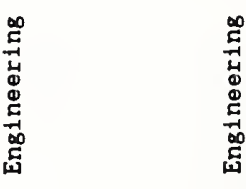




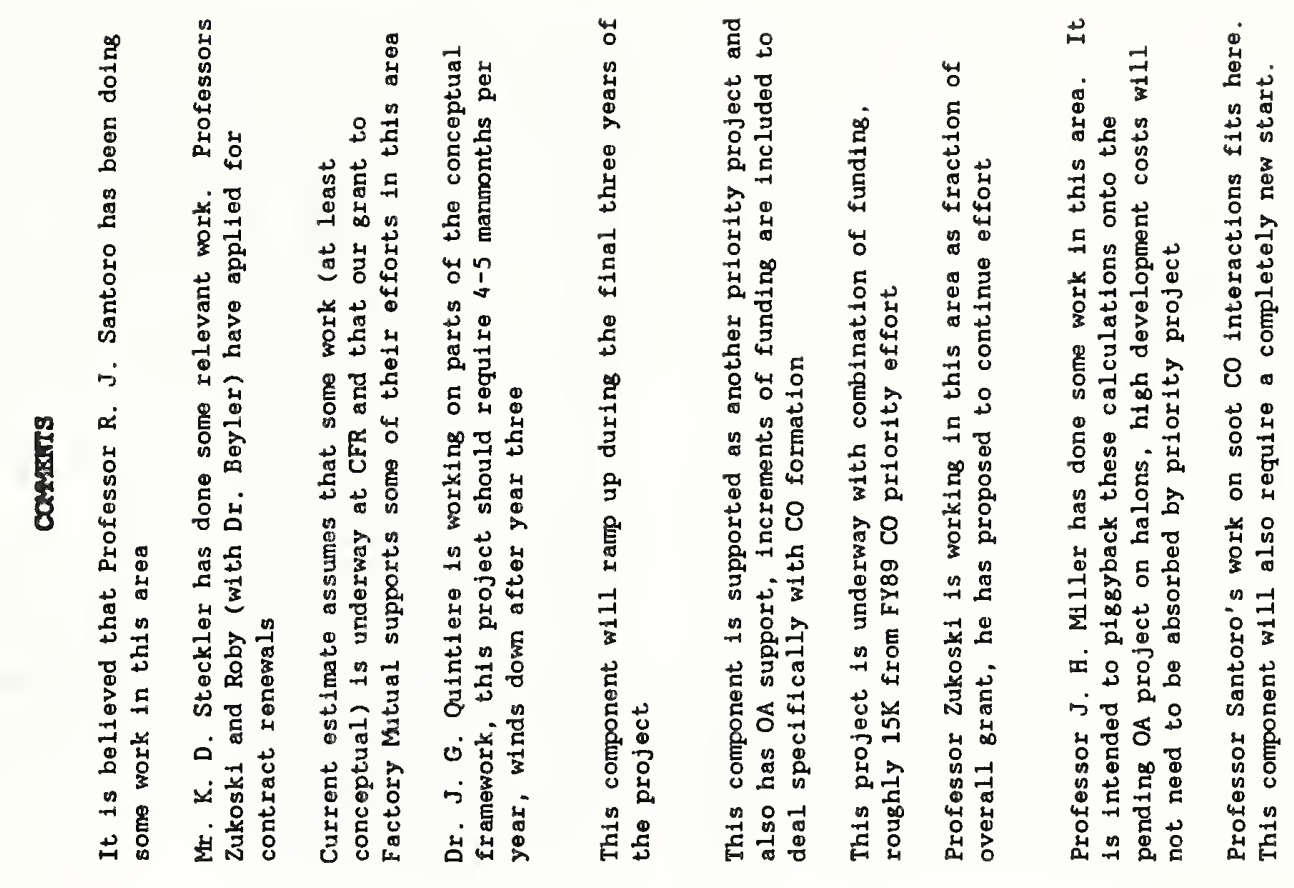

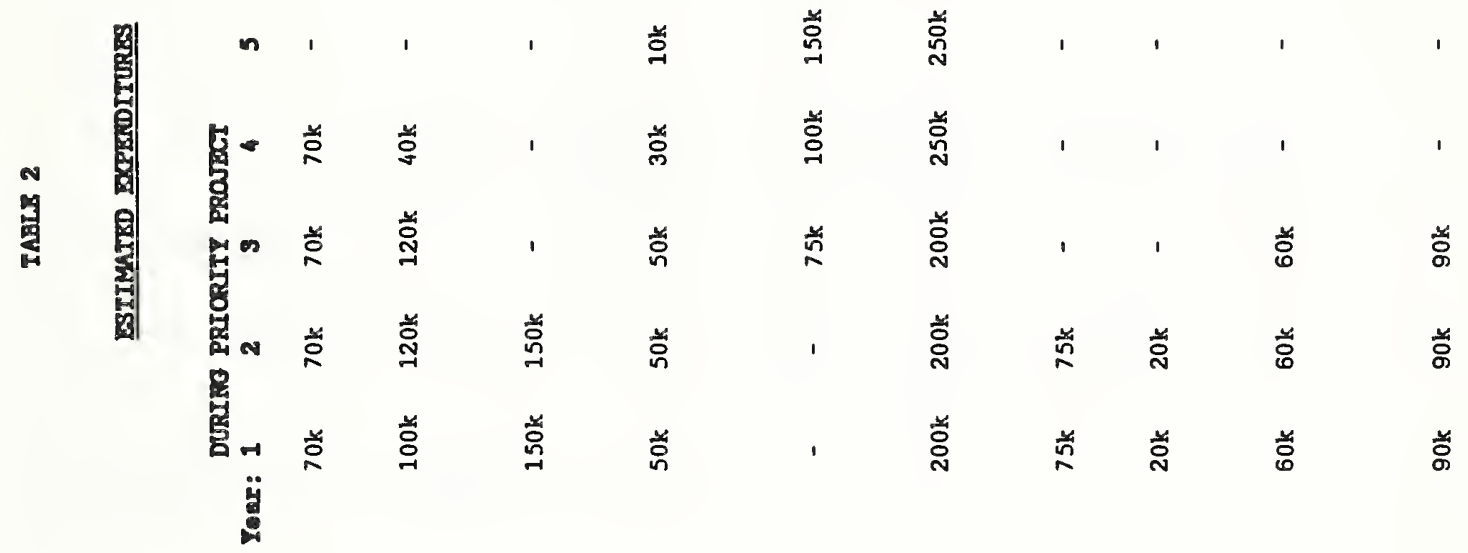

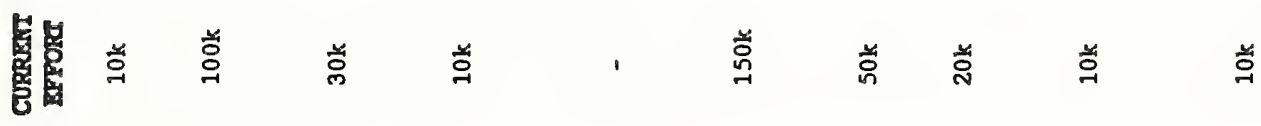

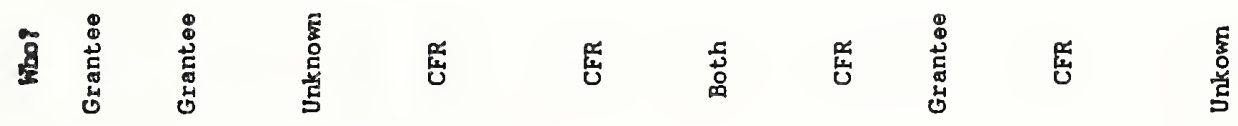

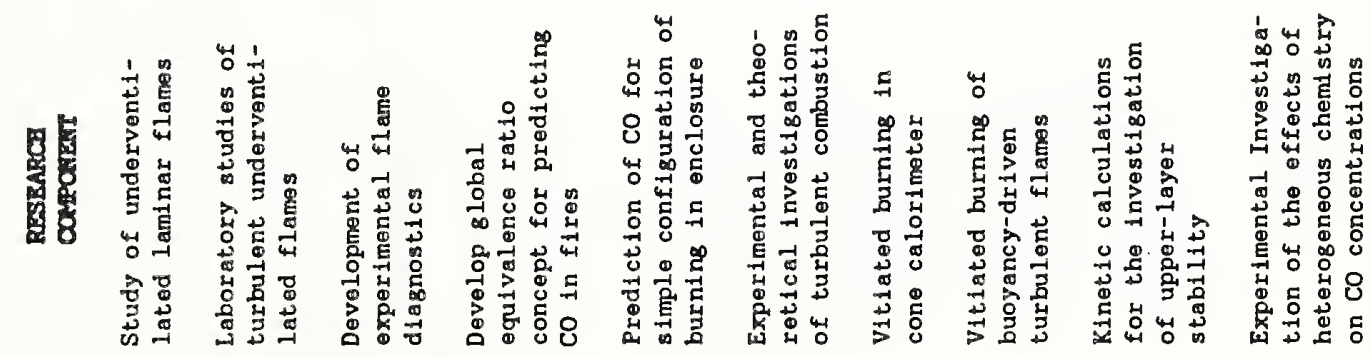




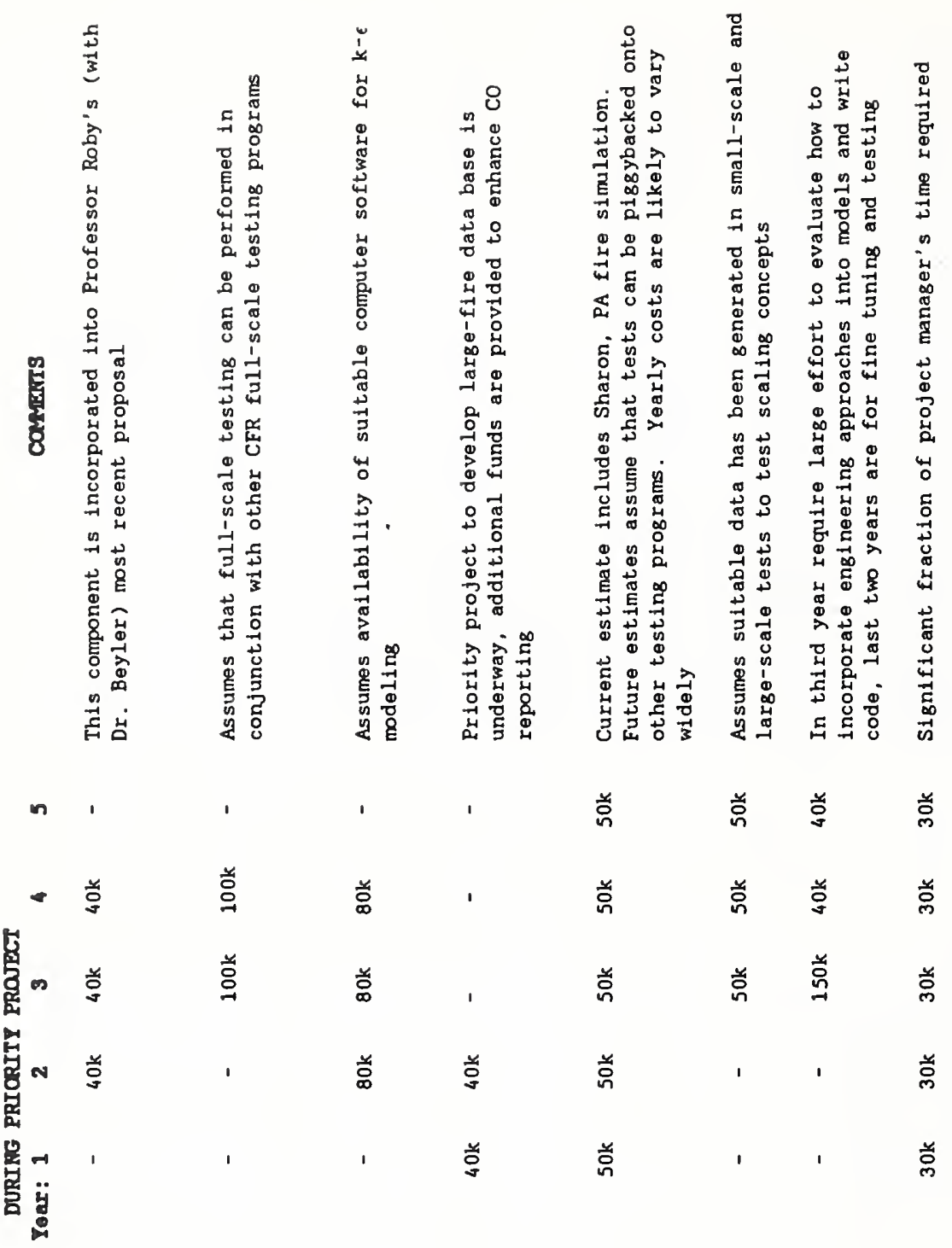

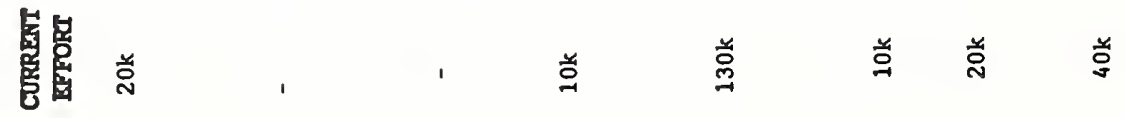

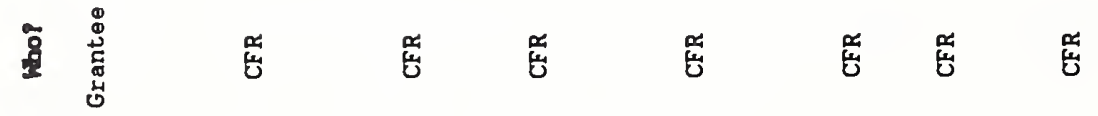

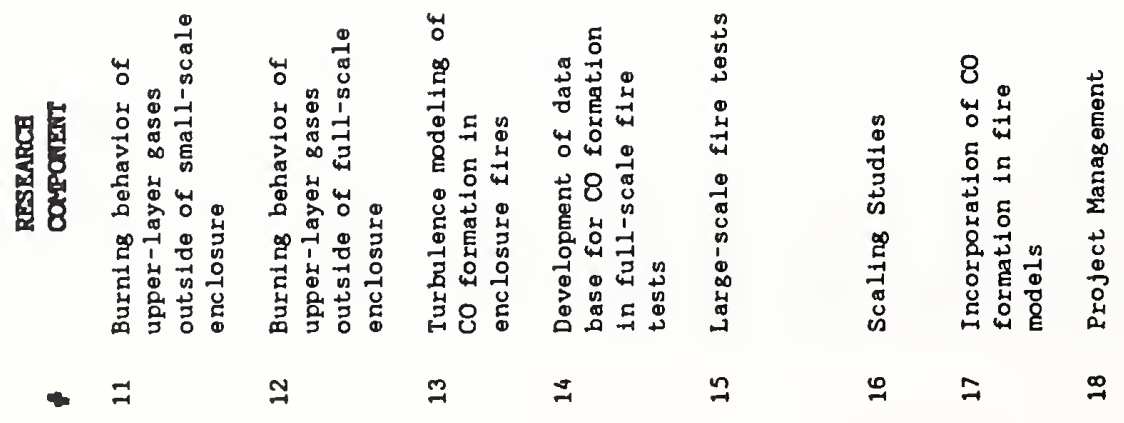


(both intramural and extramural), and projected levels of funding for the five years of the priority research plan. Since these estimates are by necessity crude, no allowance for inflation has been incorporated (i.e., the numbers are in 1989 dollars). The last column of Table 2 contains comments concerning some of the assumptions which have been utilized in making the cost estimates and projections.

Table 3 provides a summary of the current spending and projected budgets for the priority research project. Note that the budget increases over the first three years to a level roughly double that of current expenditures and then falls over the remaining two years of the effort.

\section{TABLE 3}

\begin{tabular}{clllll}
\multicolumn{6}{c}{ SUMMARY OF CURRENT AND PROJECTED EXPENDITURES } \\
$\begin{array}{cccccc}\text { CURRENT(FY89) } & \underline{\text { FY90 }} & \underline{\text { FY91 }} & \underline{\text { FY92 }} & \underline{\text { FY93 }} & \underline{\text { FY94 }} \\
620 \mathrm{k} & 935 \mathrm{k} & 1075 \mathrm{k} & 1165 \mathrm{k} & 880 \mathrm{k} & 580 \mathrm{k}\end{array}$
\end{tabular}

\section{DISCUSSION OF RESEARCH PLAN}

The discussion and tables included in Sections 7 and 8 provide a comprehensive research project plan for meeting the objectives of the $C O$ Production and Prediction priority project. In this section the reasons behind some of the choices of research components and funding levels are considered.

The two principal goals for the priority project are given in Section 6.3 (page 12). Two of the components of the project (numbers 4 and 5) deal 
specifically with these goals. Note that both are intended to be carried out by CFR staff.

The first goal is develop an engineering correlation for CO concentrations based on the global equivalence ratio concept within three years. Research component 4 provides substantial resources for the first three years to allow CFR researchers to utilize the current understanding of and ongoing research results on $\mathrm{CO}$ formation to develop the correlation necessary for inclusion into CFR fire models.

A number of the other research components are designed to feed information into this effort. Most important are numbers 2, 9, 10, 14, 15 and 16. Since results from these studies must be available before component 4 can achieve goal 1 , the time frames for these supporting efforts are heavily weighted toward the first three years of the project (see Table 1).

For planning purposes it has been assumed that a suitable engineering correlation will become available during the third year of the project. Substantial funding is included for the incorporation of the correlation (component number 17) into whichever fire model(s) is deemed appropriate.

In developing project goal 1 (see page 12) it was recognized that even though it should be possible to formulate an engineering correlation for $\mathrm{CO}$ concentration in terms of the global equivalence ratio within the first three years of the project, certain aspects of the problem can not be completed within this time frame. The burning behavior of gases exiting the enclosure is sure to be one of the remaining uncertainties. Components 11 and 12 are to address this problem. These components are funded during years 2-4. It is anticipated that a sufficient understanding of the controlling parameters will be available by year 5 to allow crude estimates of the effects of such burning 
on the CO concentration correlation. Funding is provided for component 4 in years 4 and 5 to incorporate these findings into the correlation. Any fine tuning of the correlation which is necessary as the result of new experimental findings will also be done during this period.

The second goal of the priority project deals with fundamental aspects of the problem. Success in this area has been defined as the identification of the important parameters controlling CO formation in fires, a general understanding of the success of the global equivalence ratio in correlating $C O$ production in enclosures, and the development of a model for co formation for a simple, idealized enclosure fire burning a gaseous fuel. As was true for the first goal discussed above, several of the research components deal with this aspect of the problem.

Research components $1,2,6,7,8,9,10$, and 13 are required to generate the research findings to meet the fundamental project goal. Components 1,2 , $7,8,9$, and 10 will aid in the identification of the important physical processes responsible for the formation of high levels of co during ventilation-limited burning. Note that 2, 9, and 10 are also necessary to validate the engineering correlation developed to meet the first goal of the project.

In order to have confidence in the engineering correlation which is generated, it is necessary to have some understanding of the physical basis for the success of the correlation. The fundamental studies mentioned in the last paragraph will provide the insights required to develop this understanding. At the same time, component 13 deals specifically with the question of whether or not the high levels of $\mathrm{CO}$ formed during vitiated burning can be understood simply in terms of turbulent combustion processes. 
Turbulent combustion modeling is to be employed for this purpose. Note that the experimental results of component 1 are required as input for this research. For this reason, the timing of component 13 lags behind 1 by a year.

The final goal of the fundamental studies is to develop a model capable of predicting the time development and concentrations of CO for a simple prototypical fire in an enclosure. Research component 5 deals specifically with this topic. Development of this model is slated for years $3-5$ of the project. This component is near the end of the project period because the successful development of the model will require the results of other components.

At the present time, it is not possible to state what form this model will assume. It may be found that the $k-\epsilon$ modeling approach developed during component 13 can be extended to predict the time dependence of a developing fire in an enclosure. Alternatively, this approach may prove to be inappropriate and more realistic modeling of chemically reacting turbulent flows may be necessary. Research component 6 deals with this approach. In either case, it should be possible to make a choice of direction by the end of year three. Some initial analysis is likely to be required. Resources allocated for component 13 for years 4 and 5 are to be used for the actual development of the chosen model.

The majority of research components included in Tables 1 and 2 generate research findings of direct relevance to the priority project. Components 3 and 18 do not fall into this classification. Component 18 is designed to provide overall management for the wide-ranging priority project. The 
rational for including this as a specific component is described in the following section.

Component 3 provides funding for the development of flame diagnostics. Table 2 shows that it should be funded at a level of $150 \mathrm{k}$ for the first two years of the priority project. This relatively high level of funding reflects the crucial need for these new diagnostics which has already been discussed. The members of the workshop placed a very high priority on this research area. The effort should be funded only for the first two years since developments in later years would be too late to be of value to the priority project.

The recommended level of funding is unlikely to lead to major breakthroughs in flame diagnostic technology, such breakthroughs would require much higher annual funding over a multi-year period. The recommended funding is intended to provide the incentive for careful assessment and testing of existing technologies with the goal of providing the most accurate experimental measurements possible. Existing technologies which might be explored have been discussed in Section 7.1.2.

\section{PRIORITY PROJECT PHILOSOPHY AND RESEARCH MANAGEMENT}

The complexity associated with $\mathrm{CO}$ formation and prediction in fires precludes an effective project by one or even a few individuals. As mentioned in Section 3, the current understanding of $C O$ formation is very poor despite the availability of many uncoordinated investigations. The amount of expertise required to make meaningful progress and the complexity of the problem requires that a large number of research problems be addressed and that investigators have a wide range of capabilities. 
The reality of extremely limited resources necessitates the evaluation of ways to achieve meaningful progress on the project without utilizing unrealistic amounts of new resources. Fortunately, a review of Center programs revealed (see Sections 4, 8, and 9) that a large number of research efforts are underway which have direct impact on the co project. The talent represented by this research spans a number of areas and represents a crosssection of the best fire researchers in the country. On this basis, a research plan has been formulated which builds on these existing efforts. By utilizing these existing research components (with some redirection) along with selected new research efforts, it has been possible to develop a research plan which brings significant resources to bear on the problem of co prediction within a reasonable budget. It seems likely that significant progress will be made if this research plan is implemented.

One of the most difficult aspects of the proposed research effort will be the coordination and direction of the various components. A great deal of effort will be required on the part of the project manager to stay apprised of progress on the various efforts. Minor changes in program directions which are required to meet the goals of this priority project will require negotiation with those responsible for the various components. The importance of project management is emphasized by including it as one the components in the research plan (Component 18, Tables 1 and 2).

The organization of the workshop provided an opportunity for the project manager to not only become better acquainted with many of the relevant efforts underway in the Center, but to also develop a better rapport with the researchers involved. This familiarity will prove invaluable as this very ambitious project develops. The review of the literature during the past year 
has formed the foundation for the project proposed here and at the same time has provided the tools necessary to monitor the wide range of research which has been proposed.

\section{REFERENCES}

[1] Pitts, W. M. Executive summary for the workshop on developing a predictive capability for $C O$ formation in fires. National Institute of Standards and Technology NISTIR 89-4094; 1989 May. 68 p.

[2] Harland, W. A.; Anderson, R. A. Causes of death in fires. Proceedings, Smoke and Toxic Gases from Burning Plastics; 15/1-15/19; Jan. 6-7, 1982; London, England.

[3] Harwood, B.; Hall, J. R. What kills in fires: smoke inhalation or burns? Fire J. 83: 29-34; 1989 May/June.

[4] Wilson, W. J. Large scale fire tests. J. Fire Flam. 7: 112-124; 1976.

[5] Levine, R. S.; Nelson, H. E. Full-scale simulation of Sharon, PA fatal fire: data and analysis. To appear as a National Institute of Standards and Technology Internal Report.

[6] Rasbash, D. J.; Stark, G. W. V. The generation of carbon monoxide by fires in compartments. Fire Research Station F.R. Note No. 614; 1966 Feb. $38 \mathrm{p}$.

[7] Mulholland, G. W. Position paper regarding CO yield. Letter report to Richard G. Gann, Chief, Fire Measurement and Research Division, Center for Fire Research; 1988, June 16;8 p.

[8] Beyler, C. L. Major species production by diffusion flames in a two-layer compartment fire environment. Fire Safety J. 10:47-56; 1986.

[9] Zukoski, E. E.; Toner, S. J.; Morehart, J. H.; Kubota, T. Combustion processes in two-layered configurations. Fire Safety Science.

Proceedings of the Second International Symposium. New York, NY:

Hemisphere; 1989. 295-304.

[10] Morehart, J. H.; Zukoski, E. E. Chemical species produced by natural gas fires near the extinction limit. Part of Final Report for National Institute of Standards and Technology Grant No. 60NANB600638; 1988 October. 
[11] Kee, R. J.; Miller, J. A.; Jefferson, T. H. CHEMKIN: a generalpurpose, problem-independent, transportable, Fortran chemical kinetics code package. Sandia National Laboratories Report SAND80-8003; 1980 March; 203 p.

[12] Peters, N.; Kee, R. J. The computation of stretched laminar methane-air diffusion flames using a reduced four-step mechanism. Combust. Flame 68: $17-29 ; 1987$.

[13] Peters, N. Laminar flamelet concepts in turbulent combustion. Twentyfirst Symposium (International) on Combustion. Pittsburgh, PA: The Combustion Institute; 1988. 1231-1250.

[14] Bilger, R. W. The structure of turbulent nonpremixed flames. Twentysecond Symposium (International) on Combustion; Pittsburgh, PA: The Combustion Institute; 1989. 475-488.

[15] Grosshandler, W. Personal communication.

[16] Toner, S. J.; Zukoski, E. E.; Kubota, T. Entrainment, chemistry, and structure of fire plumes. National Bureau of Standards Government Contract Report NBS-GCR-87-528; 1989 April; 200 p. 
4. TITLE AND SUBTITLE

Long-Range Plan for a Research Project on Carbon

Monoxide Production and Prediction

5. AUTHOR(S)

William M. Pitts

6. PERFORMING ORGANIZATION (If joine or other thon NBS. see instructions) NATIONAL INSTITUTE OF STANDARDS \& TECHNOLOGY

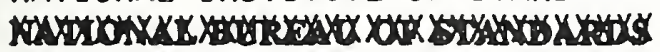

U.S. DEPARTMENT OF COMMDRCE

GATIERSBURG, MD 20899

7. Contract Grant No.

8. Type of Report \& Period Covered

9. SPONSORING ORGANIZATION NAME AND COMPLETE ADDRESS (Street, City. Stote. ZIP)

10. SUPPLEMENTARY NOTES

Document describes a computer program; SF-185, FIPS Software Summary, is attached.

11. ABSTRACT (A 200-word or less foctual summory of most significont informotion. If document includes a significont bibliography or literature survey. mention it here)

This document presents a five-year plan for the Center for Fire Research (CFR) Priority Research Project on Carbon Monoxide Prediction. Sections of the report provide a justification for the priorlty project, assess the current state of knowledge, summarize current relevant CFR research efforts, discuss specific research needs, list major assumptions utilized in formulating the research program, outline a research plan designed to meet the goals of the project and address the specific research needs, provide a rough timetable and budget, and present a discussion of the project philosophy and management.

12. KEY WORDS (Six to iwelve entries; olphobetical order; capitalize only proper nomes; and separate key words by semicolons) carbon monoxide, combustion, fire gases, fire hazard, fire prediction, toxic gases

13. AVAILABILITY

Wunlimited

$\square$ For Official Distribution. Do Not Release 10 NTIS

Order From Superintendent of Documents. U.S. Govemment Printing Office, Wastington, D.C. 20402.

X] Order From National Technical Information Service (NTIS), Springfield. VA, 22161
14. NO. OF

PRINTED PAGES

$$
44
$$

15. Price

$\mathrm{AO} 3$ 

